\title{
The effect of milrinone infusion on right ventricular function during coronary anastomosis and early outcomes in patients undergoing off-pump coronary artery bypass surgery
}

\author{
Hyong Rae Jo, Woo Kyung Lee, Yong Ho Kim, Jin Hye Min, Young Keun Chae, In Gyu Choi, Young \\ Sin Kim, and Yong Kyung Lee
}

Department of Anesthesiology and Pain Medicine, Kwandong University College of Medicine, Goyang, Korea

Background: During coronary anastomosis in off-pump coronary artery bypass surgery (OPCAB), hemodynamic alternations can be induced by impaired diastolic function of the right ventricle. This study was designed to examine the effect of milrinone on right ventricular function and early outcomes in patients undergoing OPCAB.

Methods: Forty patients undergoing OPCAB were randomly assigned in a double-blind manner to receive either milrinone (milrinone group, $\mathrm{n}=20$ ) or normal saline (control group, $\mathrm{n}=20$ ). Hemodynamic variables were measured after pericardiotomy (T1), 5 min after stabilizer application for anastomosis of the left anterior descending coronary artery (LAD, T2), the obtuse marginalis branch (OM, T3), the right coronary artery (RCA, T4), 5 min after sternal closure (T5), and after ICU arrival. The right ventricular ejection fraction (RVEF) and right ventricular volumetric parameters were also measured using the thermodilution technique. For evaluation of early outcomes, the 30-day operative mortality and morbidity risk models were used.

Results: There was no significant difference in hemodynamic variables, including mean arterial pressure, between the 2 groups, except for the cardiac index and RVEF. The cardiac index and RVEF were significantly greater at T3 in the milrinone group than in the control group.

Conclusions: Continuous infusion of milrinone demonstrated a beneficial effect on cardiac output and right ventricular function in patients undergoing OPCAB, especially during anastomosis of the graft to the OM artery, and it had no adverse effect on early outcomes. (Korean J Anesthesiol 2010; 59: 92-98)

Key Words: Milrinone, Off-pump coronary artery bypass, Right ventricular function.

Received: March 4, 2010. Revised: 1st, March 17, 2010; 2nd, April 15, 2010. Accepted: May 10, 2010.

Corresponding author: Yong Kyung Lee, M.D., Department of Anesthesiology and Pain Medicine, Kwandong University College of Medicine, 697-24, Hwajeong-dong, Deogyang-gu, Goyang 412-270, Korea. Tel: 82-31-810-6205, Fax: 82-31-810-6203, E-mail: mdtweety@naver.com (c) This is an open-access article distributed under the terms of the Creative Commons Attribution Non-Commercial License (http:// creativecommons.org/licenses/by-nc/3.0/), which permits unrestricted non-commercial use, distribution, and reproduction in any medium, provided the original work is properly cited. 


\section{Introduction}

Off-pump coronary artery bypass surgery (OPCAB) is widely performed for its benefit in reducing complications from cardiopulmonary bypass [1-3]. However, since the surgical method moves the pumping heart and limits movement of the surgery site with a tissue stabilizer, it can cause serious hemodynamic changes [4,5]. For example, the function of both ventricles declines due to pressure on the heart during OPCAB via diastolic dysfunction of the right ventricle due to pressure $[6,7]$.

Milrinone, a phosphodiesterase III inhibitor, prevents degradation of cyclic adenosine monophosphate in cardiac myocytes to increase contractile force of the heart muscle, and it relaxes the vascular smooth muscle to reduce systemic vascular resistance [8]. Milrinone helps patients avoid cardiopulmonary bypass by increasing heart function. It also enhances cardiac contractility while not increasing oxygen requirements, unlike dobutamine, and prevents vasospasm during coronary anastomosis [9]. In an animal study in canines with pulmonary hypertension, milrinone significantly improved right ventricular function and reduced pulmonary vascular resistance to improve pulmonary blood flow [10]. Milrinone also prevents reduced cardiac output and mixed venous oxygen saturation in OPCAB [11], and studies on patients with low right ventricular function show that milrinone increases the cardiac index while reducing systemic vascular resistance, showing a beneficial role in improving right ventricular function [12].

There is no research on the effects of milrinone on hemodynamic changes or even on early intensive care unit (ICU) outcomes during and after OPCAB. Lowered function of the right ventricle accompanied by heart failure increases the mortality rate [13-15], but no study has been conducted in OPCAB patients. We therefore evaluated the impact of continuous milrinone infusion using a multi-lumen cardiac thermodilution catheter on hemodynamic changes, right ventricular function, and early outcome hemodynamics.

\section{Materials and Methods}

This study was authorized by the Institutional Review Board and was conducted with OPCAB patients after written consent, before giving them anesthetic. A pilot study showed that continuous infusion of milrinone reduced the right ventricular ejection fraction (RVEF) by $20 \%$ during anastomosis of the obtuse marginal branch. This result was considered meaningful, and when setting the effect size at $0.95, \alpha$ error at 0.05 , and $\beta$ power at $0.8,19$ patients are required for each group. Considering a dropout rate of $5 \%$ from the authors' other clinical experiences, the studies were conducted with 20 patients in each group, 40 in total.

Exclusion criteria included left or right ventricular ejection fraction of less than $40 \%$ from the transthoracic echocardiogram before surgery, valvular heart disease, severe cerebral or renal dysfunction, or emergency surgery. Patients with stenosis at more than 3 coronary arteries were selected. An hour before arriving at the operating rooms, all patients received an intramuscular injection of morphine, $0.05-0.1 \mathrm{mg} / \mathrm{kg}$, as preliminary anesthesia, and other drugs, except digoxin and diuretics, as normal. After arriving at the operating room, the induction of lead II and V5 was continuously monitored by 5-leads electrocardiography, and a catheter was inserted by radial artery puncture for continuous monitoring of hemodynamics and arterial blood sampling. A pulmonary catheter (Swan-Ganz CCOmbo ${ }^{\circledR} \mathrm{CCO} / \mathrm{SvO} 2 / \mathrm{CEDV}$, Edwards Lifesciences LLC, Irvine, CA, USA), which can continuously monitor cardiac output of the right internal jugular vein, mixed venous oxygen saturation, the right ventricular ejection fraction, and right ventricular end-diastolic volume index, was inserted through an 9F introducer (AVA HF, Edwards Lifesciences, CA, USA) and monitored using a computerized monitoring system (Vigilance ${ }^{\circledR}$ CCO/SvO2/CEDV Monitor, Edwards Lifesciences, CA, USA).

For inducing anesthesia, endotracheal intubation was performed after giving intravenous injections of midazolam $2.5 \mathrm{mg}$, sufentanil $1.5-3.0 \mu \mathrm{g} / \mathrm{kg}$, and rocuronium bromide 50 $\mathrm{mg}$. To maintain anesthesia, sufentanil $(0.5-1.5 \mu \mathrm{g} / \mathrm{kg} / \mathrm{h})$ and vecuronium were continuously administered intravenously with $50 \%$ oxygen and $50 \%$ medical air, as well as sevoflurane with an end-tidal concentration of $0.2-0.4 \mathrm{vol} \%$, and controlled ventilation was conducted to set the end-tidal $\mathrm{CO}_{2}$ tension at 30-35 mmHg. After inducing anesthesia, isosorbide dinitrate $(0.5 \mu \mathrm{g} / \mathrm{kg} / \mathrm{min})$ was administered to prevent myocardial ischemia and coronary vasospasm, and a transesophageal echocardiography probe was inserted to continuously monitor cardiac movement from a short-axis mid-papillary muscle view, which shows the left ventricular papillary muscle, or a 4- or 2-chamber view if monitoring was difficult. Moreover, the temperature of the operating room was kept at over $20^{\circ} \mathrm{C}$. To maintain blood temperature, as measured by pulmonary artery catheter, at over $35.5^{\circ} \mathrm{C}$, a warm mattress, warming blanket, infusion blood warmer, and humidifier with heated wire breathing circuit were used. During dissection of the internal mammary artery for a graft after median sternotomy, an infusion solution of 1,500-2,000 $\mathrm{ml}$ was injected for 2 hours to maintain preload of the heart, and then the infusion solution was injected intravenously at a speed of $6-8 \mathrm{ml} / \mathrm{kg} /$ $\mathrm{hr}$ to keep the volume at a similar level as post-anesthesia induction while monitoring the left ventricular end-diastolic volume from echocardiography. After performing sternotomy, 
patients received saline $(n=20$, controls) or milrinone ( $\mathrm{n}=20$, Sanofi, Korea) $0.5 \mu \mathrm{g} / \mathrm{kg} / \mathrm{min}$ during coronary artery anastomosis. After finishing the dissection of the internal mammary artery, heparin $1 \mathrm{mg} / \mathrm{kg}$ was injected intravenously and activated coagulation time was maintained at over 250 seconds. The heart was elevated using a pericardial suture and gauze and rotated to clear vision, and then the movement of blood vessels for vascular anastomosis was prevented with the Octopus Tissue Stabilization system ${ }^{\circledR}$, Medtronic Inc. USA. Vascular anastomosis was started with the left anterior descending artery (LAD), obtuse marginal branch (OM), and right coronary artery (RCA) to the posterior descending artery (PDA); and a shunt (Florester ${ }^{\circledR}$, Bio-Vascular Co., USA) inside the coronary artery was used to maintain coronary flow during the operation. All procedures were performed by the same cardiac surgeon and anesthesiologist blinded to the treatment groups. For hypotension during proximal anastomosis of each coronary artery, the Trendelenburg position at 15$20^{\circ}$ was taken, and for hypotension during elevating heart or anastomosis, norepinephrine $(8 \mu \mathrm{g} / \mathrm{ml})$ was given to keep the mean arterial pressure over $70 \mathrm{mmHg}$. A measurement of the variables was conducted after pericardiotomy ( $\mathrm{T} 1$, base value), every 5 minutes after attaching a cardiac tissue stabilizer for anastomosis of the left anterior descending artery, obtuse marginal and posterior descending artery of the right coronary artery (each LAD:T2, OM:T3 and PDA:T4) and after performing sternum closure (T5); and the time of measuring hemodynamic variables in the intensive care unit was immediately, 6 hours after, and 12 hours after arrival in the intensive care unit.

Table 1. Patient Characteristics

\begin{tabular}{lcc}
\hline & $\begin{array}{c}\text { Control group } \\
(\mathrm{n}=20)\end{array}$ & $\begin{array}{c}\text { Milrinone group } \\
(\mathrm{n}=20)\end{array}$ \\
\hline Age (yr) & $64.1 \pm 9.9$ & $67.0 \pm 9.2$ \\
Sex (M/F) & $11 / 9$ & $12 / 8$ \\
Height (cm) & $158.3 \pm 25.4$ & $161.2 \pm 11.8$ \\
Weight (kg) & $71.2 \pm 24.1$ & $66.6 \pm 14.9$ \\
BSA (m $\left.{ }^{2}\right)$ & $1.7 \pm 0.1$ & $1.6 \pm 0.2$ \\
Left ventricular ejection fraction (\%) & $51.1 \pm 13.3$ & $45.4 \pm 14.0$ \\
Comorbid risk factors (n) & & \\
Hypertension & 11 & 11 \\
Diabetes mellitus & 7 & 9 \\
Previous myocardial infarction & 3 & 4 \\
Transient ischemic accident & 2 & 2 \\
Preoperative medication (n) & & 14 \\
Beta blocker & 13 & 15 \\
Calcium channel antagonist & 16 & 0 \\
ACE inhibitor & 12 & 2 \\
Digoxin & 1 & 2 \\
Diuretics & & \\
\hline
\end{tabular}

All values are presented as number of patients or mean \pm SD. M/ F: male/female, BSA: body surface area, ACE inhibitor: angiotensin converting enzyme inhibitors.
Variables included heart rate, mean arterial pressure, central venous pressure, mean pulmonary artery pressure, pulmonary capillary wedge pressure, mixed venous oxygen saturation, cardiac output, right ventricular volume index, and right ventricular ejection fraction. The systemic vascular resistance index and pulmonary vascular resistance index were calculated while recording the administered volume of norepinephrine. Also, to monitor and compare early outcomes, we recorded permanent cerebral infarction for 30 days after the operation, as suggested by the Society of Thoracic Surgeons, renal insufficiency, mechanical ventilation lasting more than 48 hours, deep sternal infection, re-operation, and the mortality rate [16]. Renal failure was defined as when serum creatine increased more than 2.0 after the operation was performed, when it increased more than $50 \%$ compared to the base value before the operation, or when dialysis was required. SPSS 12.0 (SPSS Inc., Chicago, IL, USA) was used for statistical analysis, and all values are given as the average \pm standard deviation or the number of patients. To compare groups, an independent t-test was used for continuous data, and Fisher's exact test and the chi-square test were used to evaluate categorical data. Comparisons between base and measured values over time was conducted with a paired t-test after setting the estimated value as the control value after performing pericardiotomy. $\mathrm{P}<0.05$ was considered significant.

\section{Results}

OPCAB was performed successfully without transition to emergency cardiopulmonary bypass. There were no significant statistical differences between the 2 groups for gender, age, medical history of diabetes and hypertension, drug administration, or left ventricle ejection rate (Table 1). The total operation time, coronary artery anastomosis, and total norepinephrine volume were similar for both groups (Table 2). Heart movement and stabilization for anastomosis did not require treatment of arrhythmia.

Cardiac index decreased in controls during OM anastomosis, whereas milrinone treatment increased it $(\mathrm{P}<0.05$, Table 3$)$. Milrinone also blocked the increase in pulmonary vascular

Table 2. Surgical Data and Amount of Norepinephrine during Coronary Artery Anastomosis

\begin{tabular}{lcc}
\hline & Control group & Milrinone group \\
\hline Number of graft $(\mathrm{n})$ & $3.1 \pm 0.9$ & $3.4 \pm 1.0$ \\
Duration of surgery (min) & $285.1 \pm 25.4$ & $309.5 \pm 31.2$ \\
Anastomosis time (min) & $85.5 \pm 31.0$ & $93.2 \pm 27.1$ \\
Norepinephrine $(\mu \mathrm{g})$ & $301.4 \pm 297.4$ & $289.9 \pm 276.2$ \\
\hline
\end{tabular}

All values are presented as mean \pm SD. 
Table 3. Changes in Hemodynamic Variables during Coronary Artery Anastomosis

\begin{tabular}{|c|c|c|c|c|c|c|}
\hline & Group & $\mathrm{T} 1$ & $\mathrm{~T} 2$ & T3 & $\mathrm{T} 4$ & T5 \\
\hline \multirow[t]{2}{*}{ HR (Beats/min) } & Control & $70 \pm 16$ & $77 \pm 16^{\dagger}$ & $78 \pm 15^{\dagger}$ & $78 \pm 13^{\dagger}$ & $73 \pm 15$ \\
\hline & Milrinone & $72 \pm 15$ & $80 \pm 14^{\dagger}$ & $88 \pm 15^{\dagger}$ & $89 \pm 9^{\dagger}$ & $89 \pm 10$ \\
\hline \multirow[t]{2}{*}{ MAP (mmHg) } & Control & $84 \pm 13$ & $78 \pm 10$ & $78 \pm 11$ & $78 \pm 8$ & $80 \pm 9$ \\
\hline & Milrinone & $82 \pm 12$ & $74 \pm 12$ & $73 \pm 10$ & $75 \pm 9$ & $73 \pm 17$ \\
\hline \multirow[t]{2}{*}{ MPAP (mmHg) } & Control & $20 \pm 8$ & $25 \pm 6^{\dagger}$ & $24 \pm 9^{+}$ & $27 \pm 5^{\dagger}$ & $20 \pm 6$ \\
\hline & Milrinone & $19 \pm 4$ & $21 \pm 7$ & $20 \pm 7$ & $23 \pm 6^{\dagger}$ & $18 \pm 5$ \\
\hline \multirow[t]{2}{*}{ CVP (mmHg) } & Control & $10 \pm 5$ & $9 \pm 2$ & $12 \pm 6$ & $15 \pm 2^{\dagger}$ & $10 \pm 3$ \\
\hline & Milrinone & $9 \pm 3$ & $7 \pm 2$ & $9 \pm 3$ & $14 \pm 2^{\dagger}$ & $9 \pm 2$ \\
\hline \multirow[t]{2}{*}{ PCWP (mmHg) } & Control & $16 \pm 8$ & $18 \pm 6$ & $17 \pm 9$ & $19 \pm 4$ & $14 \pm 5$ \\
\hline & Milrinone & $13 \pm 3$ & $14 \pm 4$ & $13 \pm 4$ & $16 \pm 4$ & $13 \pm 2$ \\
\hline \multirow[t]{2}{*}{$\mathrm{SvO} 2(\%)$} & Control & $77 \pm 4$ & $77 \pm 7$ & $73 \pm 9$ & $58 \pm 6^{\dagger}$ & $73 \pm 9$ \\
\hline & Milrinone & $75 \pm 2$ & $71 \pm 7$ & $65 \pm 11^{\dagger}$ & $66 \pm 9^{\dagger}$ & $70 \pm 4$ \\
\hline \multirow[t]{2}{*}{$\mathrm{CI}\left(\mathrm{L} / \mathrm{min} / \mathrm{m}^{2}\right)$} & Control & $2.7 \pm 0.4$ & $2.6 \pm 0.5$ & $2.0 \pm 0.4^{\dagger}$ & $2.4 \pm 0.7$ & $3.0 \pm 0.7$ \\
\hline & Milrinone & $2.5 \pm 0.6$ & $2.9 \pm 0.4$ & $2.9 \pm 0.4^{*}$ & $2.8 \pm 0.7$ & $2.9 \pm 0.6$ \\
\hline \multirow[t]{2}{*}{ SVRI (dyn $\cdot s / \mathrm{cm}^{5} / \mathrm{m}^{2}$ ) } & Control & $866 \pm 355$ & $1,053 \pm 260$ & $1,208 \pm 325^{\dagger}$ & $1,076 \pm 272$ & $987 \pm 268$ \\
\hline & Milrinone & $913 \pm 263$ & $756 \pm 293$ & $839 \pm 304$ & $809 \pm 246$ & $851 \pm 32$ \\
\hline \multirow[t]{2}{*}{ PVRI (dyn $\cdot \mathrm{s} / \mathrm{cm}^{5} / \mathrm{m}^{2}$ ) } & Control & $64 \pm 50$ & $91 \pm 51$ & $125 \pm 33^{\dagger}$ & $94 \pm 44$ & $62 \pm 29$ \\
\hline & Milrinone & $63 \pm 26$ & $49 \pm 38^{*}$ & $79 \pm 44^{*}$ & $82 \pm 34$ & $57 \pm 17$ \\
\hline
\end{tabular}

All values are presented as mean \pm SD. HR: heart rate, MAP: mean arterial pressure, MPAP: mean pulmonary arterialpressure, CVP: central venous pressure, PCWP: pulmonary capillary wedge pressure, SvO2: mixed venous oxygen saturation, CI: cardiac index, SVRI: systemic vascular resistance index, PVR: pulmonary vascular resistance index, T1: after pericardiotomy, T2, T3 and T4: 5 minutes after stabilizer application for anastomosis of the left anterior descending coronary artery (T2), obtuse marginalis artery (T3), and posterior descending artery of right coronary artery (T4), T5: 5 minutes after sternum closure. ${ }^{*} \mathrm{P}<0.05$ between the two groups, ${ }^{\dagger} \mathrm{P}<0.05$ compared to values at T1 in each group.

Table 4. Right Ventricular Volumetric Data during Coronary Artery Anastomosis

\begin{tabular}{llccccc}
\hline & & T1 & T2 & T3 & T4 & T5 \\
\hline RVEF $(\%)$ & Control & $28 \pm 6$ & $30 \pm 8$ & $23 \pm 5$ & $27 \pm 5$ & $32 \pm 8$ \\
$\operatorname{RVESVI}\left(\mathrm{ml} / \mathrm{m}^{2}\right)$ & Milrinone & $27 \pm 5$ & $29 \pm 7$ & $31 \pm 6 *$ & $29 \pm 5$ & $31 \pm 4$ \\
& Control & $90 \pm 20$ & $91 \pm 21$ & $85 \pm 25$ & $84 \pm 14$ & $88 \pm 22$ \\
$\operatorname{RVEDVI}\left(\mathrm{ml} / \mathrm{m}^{2}\right)$ & Milrinone & $98 \pm 33$ & $105 \pm 37$ & $79 \pm 28$ & $98 \pm 30$ & $93 \pm 50$ \\
& Control & $129 \pm 18$ & $131 \pm 24$ & $122 \pm 24$ & $125 \pm 16$ & $129 \pm 21$ \\
& Milrinone & $129 \pm 32$ & $134 \pm 41$ & $114 \pm 30$ & $127 \pm 32$ & $125 \pm 51$
\end{tabular}

All values are presented as mean \pm SD. RVEF: right ventricular ejection fraction, RVESVI: right ventricular end systolic volume index, RVEDVI: right ventricular end diastolic volume index, T1: after pericardiotomy, T2, T3 and T4: 5 minutesafter stabilizer application for anastomosis of the left anterior descending coronary artery (T2), obtuse marginalis artery (T3), and posterior descending artery of right coronary artery (T4), T5: 5 minutes after sternum closure. $* \mathrm{P}<0.05$ between the two groups.

resistance index during $\mathrm{LAD}$ and $\mathrm{OM}$ anastomosis $(\mathrm{P}<0.05$, Table 3). Milrinone also increased the right ventricular ejection fraction during anastomosis, but did not change other variables (P $<0.05$, Table 4). During anastomosis, mean arterial pressure remained steady but heart rate increased with time. Pulmonary artery pressure increased during anastomosis in controls, but only during PDA anastomosis in the milrinone group. Central venous pressure was increased for both groups during PDA anastomosis. Mixed venous oxygen saturation decreased in the milrinone group during $\mathrm{OM}$ anastomosis, and in both groups during PDA anastomosis. The cardiac index decreased significantly compared to baseline during OM anastomosis for controls, whereas the systemic vascular resistance index and pulmonary vascular resistance index were increased significantly during $\mathrm{OM}$ anastomosis $(\mathrm{P}<0.05$, Table 3$)$.
The hemodynamic variables checked immediately after arrival in the ICU, 6 hours after arriving, and 12 hours after arriving did not show significant gaps between the groups (Table 5), and there were no early deaths; both groups showed similar rates of myocardial infarction, cerebral infarction, renal failure, mechanical ventilation lasting more than 48 hours, reoperation, and infections (Table 6).

\section{Discussion}

The study focused on the effect of milrinone infusion on right ventricular function during coronary anastomosis and early outcomes in patients undergoing OPCAB. Milrinone infusion prevented reductions in the right ventricular ejection fraction during anastomosis of the obtuse marginal artery, on the 
Table 5. ICU Hemodynamic Data

\begin{tabular}{|c|c|c|c|c|}
\hline & Group & Arrival & ICU 6 hr & ICU $12 \mathrm{hr}$ \\
\hline \multirow[t]{2}{*}{ HR (beats/min) } & Control & $82 \pm 15$ & $77 \pm 16$ & $72 \pm 15$ \\
\hline & Milrinone & $84 \pm 13$ & $81 \pm 14$ & $79 \pm 15$ \\
\hline \multirow[t]{2}{*}{ MAP (mmHg) } & Control & $85 \pm 13$ & $81 \pm 11$ & $76 \pm 13$ \\
\hline & Milrinone & $81 \pm 13$ & $78 \pm 11$ & $75 \pm 10$ \\
\hline \multirow[t]{2}{*}{ MPAP (mmHg) } & Control & $24 \pm 9$ & $22 \pm 7$ & $22 \pm 9$ \\
\hline & Milrinone & $21 \pm 5$ & $24 \pm 9$ & $24 \pm 7$ \\
\hline \multirow[t]{2}{*}{ CVP (mmHg) } & Control & $13 \pm 5$ & $10 \pm 2$ & $11 \pm 6$ \\
\hline & Milrinone & $12 \pm 3$ & $9 \pm 2$ & $9 \pm 3$ \\
\hline \multirow{2}{*}{ PCWP (mmHg) } & Control & $17 \pm 8$ & $17 \pm 6$ & $16 \pm 9$ \\
\hline & Milrinone & $14 \pm 3$ & $13 \pm 4$ & $13 \pm 7$ \\
\hline \multirow[t]{2}{*}{ SvO2 (\%) } & Control & $78 \pm 4$ & $76 \pm 8$ & $74 \pm 9$ \\
\hline & Milrinone & $73 \pm 2$ & $74 \pm 7$ & $70 \pm 11$ \\
\hline \multirow[t]{2}{*}{$\mathrm{CI}\left(\mathrm{L} / \mathrm{min} / \mathrm{m}^{2}\right)$} & Control & $2.8 \pm 0.4$ & $2.6 \pm 0.3$ & $2.9 \pm 0.4$ \\
\hline & Milrinone & $2.9 \pm 0.6$ & $3.0 \pm 0.6$ & $3.4 \pm 0.4$ \\
\hline \multirow[t]{2}{*}{ SVRI (dyn·s $\left./ \mathrm{cm}^{5} / \mathrm{m}^{2}\right)$} & Control & $745 \pm 326$ & $756 \pm 312$ & $773 \pm 225$ \\
\hline & Milrinone & $790 \pm 243$ & $772 \pm 279$ & $812 \pm 310$ \\
\hline \multirow[t]{2}{*}{ PVRI (dyn.s $/ \mathrm{cm}^{5} / \mathrm{m}^{2}$ ) } & Control & $74 \pm 50$ & $61 \pm 51$ & $75 \pm 33$ \\
\hline & Milrinone & $63 \pm 26$ & $59 \pm 38$ & $70 \pm 44$ \\
\hline \multirow[t]{2}{*}{ RVEF (\%) } & Control & $29 \pm 3$ & $32 \pm 8$ & $33 \pm 5$ \\
\hline & Milrinone & $31 \pm 6$ & $33 \pm 7$ & $34 \pm 6$ \\
\hline \multirow[t]{2}{*}{$\operatorname{RVESVI}\left(\mathrm{ml} / \mathrm{m}^{2}\right)$} & Control & $88 \pm 21$ & $91 \pm 21$ & $95 \pm 27$ \\
\hline & Milrinone & $90 \pm 33$ & $112 \pm 37$ & $89 \pm 28$ \\
\hline \multirow[t]{2}{*}{$\operatorname{RVEDVI}\left(\mathrm{ml} / \mathrm{m}^{2}\right)$} & Control & $132 \pm 18$ & $135 \pm 27$ & $132 \pm 24$ \\
\hline & Milrinone & $129 \pm 32$ & $134 \pm 41$ & $144 \pm 20$ \\
\hline
\end{tabular}

All values are presented as mean \pm SD. ICU: intensive care unit, HR: heart rate, MAP: mean arterial pressure, MPAP: mean pulmonary arterial pressure, CVP: central venous pressure, PCWP: pulmonary capillary wedge pressure, SvO2: mixed venous oxygen saturation, CI: cardiac index, SVRI: systemic vascular resistance index, PVRI: pulmonary vascular resistance index, RVEF: right ventricular ejection fraction, RVESVI: right ventricular end systolic volume index, RVEDVI: right ventricular end diastolic volume index.

posterior slope of the heart, and did not greatly influence early outcomes. OPCAB can reduce the incidence of complications related with external circulation, including pulmonary dysfunction, kidney injury, brain injury, and hematoma, but can cause hemodynamic instability when the heart is elevated and stabilized for the anastomosis $[17,18]$. Elevating the heart vertically to expose blood vessels for anastomosis decreases cardiac output and blood pressure and increases central venous pressure, but reducing central venous pressure with a pump that delivers blood to the pulmonary artery via cannulation of the right atrium increased right heart function and improved hemodynamic instability in animals [19]. Increasing ventricular preload by postural changes, including the head-down tilt position, helps maintain ventricular function [20]. Dysfunction of the right ventricle from stabilizer pressure can cause hemodynamic disorders during OPCAB, particularly during vascular anastomosis of the posterior border of the heart [21]. For most OPCAB patients, coronary artery anastomosis does not cause serious hemodynamic disorders, but obtuse marginal artery anastomosis on the posterior border of heart can decrease both right and left ventricle
Table 6. 30-day Operative Morbidity Results

\begin{tabular}{lcc}
\hline & $\begin{array}{c}\text { Control group } \\
(\mathrm{n}=20)\end{array}$ & $\begin{array}{c}\text { Milrinone group } \\
(\mathrm{n}=20)\end{array}$ \\
\hline Stroke & 1 & 0 \\
Renal failure & 2 & 1 \\
Prolonged ventilation & 2 & 2 \\
Reoperation & 0 & 1 \\
Sternal infection & 0 & 1 \\
\hline
\end{tabular}

All values are number of patients.

function [22,23]; milrinone infusion could block the decreases in cardiac index during obtuse marginal artery anastomosis and the right ventricular ejection fraction. Right ventricle function significantly influences left ventricle function through interdependence, and shows a close interrelationship with congestive heart failure and the short-and-long-term survival rate of OPCAB patients [13,14,24]. Milrinone improved RVEF by enhancing left ventricle function, increasing the cardiac index, and decreasing systemic vascular resistance, as well as improving right ventricular function by blocking increases in pulmonary vascular resistance. Milrinone increases the cardiac index for congestive heart failure patients at plasma concentrations of $66-427 \mathrm{ng} / \mathrm{ml}$ [25]. Continuous intravenous injection of milrinone at $0.5 \mu \mathrm{g} / \mathrm{kg} / \mathrm{min}$ after bolus injection of $50 \mu \mathrm{g} / \mathrm{kg}$ brought plasma concentrations up to $100 \mathrm{ng} / \mathrm{ml}$, and the infusion rate was appropriate for the treatment of weaning of cardiopulmonary bypass [26]; the milrinone infusion rate of $0.5 \mu \mathrm{g} / \mathrm{kg} / \mathrm{min}$ produces plasma concentrations of $100-300 \mathrm{ng} /$ ml. A bolus loading of milrinone ,may cause hypotension [27], but continuous intravenous injection alone (without bolus) can produce effective plasma concentrations within an hour [28]. Milrinone injection was started after sternotomy and reached effective levels because it requires more than 1 hour from excoriating the internal mammal artery to coronary artery anastomosis. Although milrinone can induce hypotension and arrhythmia, we did not observe these side effects here. The RVEF, as estimated by a pulmonary artery catheter using the thermodilution method, reflects right ventricle function with high reliability and reproducibility $[29,30]$. Thermodilution may be more reliable than transesophageal echocardiography (TEE) [31] for measuring right ventricle function during surgery. The RVEF using a pulmonary artery catheter is sensitive to preload changes, but we did not detect differences in the right ventricular diastole volume index, a measure of preload. OPCAB patients have chronic ischemic heart disease due to a drastic decline of coronary artery blood flow to both ventricles, so transitioning the heart to the coronary artery site for anastomosis would worsen the function of both ventricles by reducing cardiac output [32]. In particular, because the obtuse marginal artery produces more functional disorders than other 
coronary arteries during anastomosis, intensive monitoring and treatment of ischemic heart disease is required to avoid declines in ventricle function [19]. Milrinone may therefore stabilize ventricle function during obtuse marginal artery anastomosis, as assessed by the RVEF and cardiac index via a pulmonary artery catheter. The Society of Thoracic Surgeons measures early $\mathrm{OPCAB}$ outcomes such as mortality rate within 30 days, stroke, renal failure, reoperation, continuous mechanical ventilation, and infection frequency of the sternum [16]. Both groups showed a similar complication rate, indicating that milrinone does not affect early outcomes.

One limitation of our research is that RVEF using a pulmonary artery catheter is very sensitive to preload and afterload, which may change based on patient position. Secondly, complication rates were similar in both groups, but larger studies are needed to confirm this. Thirdly, the time of obtuse marginal artery anastomosis may be less than 10 minutes on average, meaning that it is clinically meaningless for the ischemic preconditioning heart. Lastly, we only included patients with normal left ventricle function, and further work should include patients with abnormal ventricular function.

In conclusion, milrinone infusion during OPCAB surgery blocked reductions in RVEF during obtuse marginal artery anastomosis and maximal levels of hemodynamic instability with similar complication rates as controls.

\section{References}

1. Buffolo E, de Andrade CS, Branco JN, Teles CA, Aguiar LF, Gomes WJ. Coronary artery bypass grafting without cardiopulmonary bypass. Ann Thorac Surg 1996; 61: 63-6.

2. Jansen EW, Gründeman PF, Borst C, Eefting F, Diephuis J, Nierich A, et al. Less invasive off-pump CABG using a suction device for immobilization: the 'Octopus' method. Eur J Cardiothorac Surg 1997; 12: 406-12.

3. Hart JC, Spooner TH, Pym J, Flavin TF, Edgerton JR, Mack MJ, et al. A review of 1,582 consecutive Octopus off-pump coronary bypass patients. Ann Thorac Surg 2000; 70: 1017-20.

4. Cartier R, Blain R. Off-pump revascularization of the circumflex artery: technical aspect and short-term results. Ann Thorac Surg 1999; 68: 94-9.

5. Jansen EW, Borst C, Lahpor JR, Gründeman PF, Eefting F, Nierich A, et al. Coronary artery bypass grafting without cardiopulmonary bypass using the octopus method: results in the first one hundred patients. J Thorac Cardiovasc Surg 1998; 116: 60-7.

6. Gründeman PF, Borst C, Verlaan CW, Meijburg H, Mouës CM, Jansen EW. Exposure of circumflex branches in the tilted, beating porcine heart: echocardiographic evidence of right ventricular deformation and the effect of right or left heart bypass. J Thorac Cardiovasc Surg 1999; 118: 316-23.

7. Nierich AP, Diephuis J, Jansen EW, Borst C, Knape JT. Heart displacement during off-pump CABG: how well is it tolerated? Ann
Thorac Surg 2000; 70: 466-72

8. Borow KM, Come PC, Neumann A, Baim DS, Braunwald E, Grossman W. Physiologic assessment of the inotropic, vasodilator and afterload reducing effects of milrinone in subjects without cardiac disease. Am J Cardiol 1985; 55: 204-9.

9. Levy JH, Bailey JM, Deeb GM. Intravenous milrinone in cardiac surgery. Ann Thorac Surg 2002; 73: 325-30.

10. Chen EP, Bittner HB, Davis RD Jr, Van Trigt P 3rd. Milrinone improves pulmonary hemodynamics and right ventricular function in chronic pulmonary hypertension. Ann Thorac Surg 1997; 63: 814-21.

11. Kwak YL, Oh YJ, Shinn HK, Yoo KJ, Kim SH, Hong YW. Haemodynamic effects of a milrinone infusion without a bolus in patients undergoing off-pump coronary artery bypass graft surgery. Anaesthesia 2004; 59: 324-31.

12. Lee JH, Oh YJ, Shim YH, Hong YW, Yi G, Kwak YL. The effect of milrinone on the right ventriclular function in patients with reduced right ventricular function undergoing off-pump coronary artery bypass graft surgery. J Korean Med Sci 2006; 21: 854-8.

13. Maslow AD, Regan MM, Panzica P, Heindel S, Mashikan J, Comunale ME. Precardiopulmonary bypass right ventricular function is associated with poor outcome after coronary bypass grafting in patients with severe left ventricular systolic dysfunction. Anesth Analg 2002; 95: 1507-18.

14. de Groote P, Millaire A, Foucher-Hossein C, Nugue O, Marchandise $\mathrm{X}$, Ducloux G. Right ventricular ejection fraction is an independent predictor of survival in patients with moderate heart failure. J Am Coll Cardiol 1998; 32: 948-54.

15. Meyer P, Filippatos GS, Ahmed MI, Iskandrian AE, Bittner V, Perry GJ, et al. Effects of right ventricular ejection fraction on outcomes in chronic systolic heart failure. Circulation 2010; 121: 252-8.

16. Shroyer AL, Coombs LP, Peterson ED, Eiken MC, DeLong ER, Chen A, et al. The Society of Thoracic Surgeons: 30-day operative mortality and morbidity risk models. Ann Thorac Surg 2003; 75 : 1856-64.

17. Lee JH, Abdelhady K, Capdeville M. Clinical outcomes and resource usage in 100 consecutive patients after off-pump coronary bypass procedures. Surgery 2000; 128: 548-55.

18. Nierich AP, Diephuis J, Jansen EW, van Dijk D, Lahpor JR, Borst C, et al. Embracing the heart: perioperative management of patients undergoing off-pump coronary artery bypass grafting using the octopus tissue stabilizer. J Cardiothorac Vasc Anesth 1999; 13: 123-9.

19. Porat E, Sharony R, Ivry S, Ozaki S, Meyns BP, Flameng WJ, et al. Hemodynamic changes and right heart support during vertical displacement of the beating heart. Ann Thorac Surg 2000; 69: 1188-91.

20. Gründeman PF, Borst C, van Herwaarden JA, Mansvelt Beck HJ, Jansen EW. Hemodynamic changes during displacement of the beating heart by the Utrecht Octopus method. Ann Thorac Surg 1997; 63(Suppl 6): S88-92.

21. Mathison M, Edgerton JR, Horswell JL, Akin JJ, Mack MJ. Analysis of hemodynamic changes during beating heart surgical procedures. Ann Thorac Surg 2000; 70: 1355-60; discussion 1360-1.

22. Kim KB, Kang CH, Chang WI, Lim C, Kim JH, Ham BM, et al. Offpump coronary artery bypass with complete avoidance of aortic manipulation. Ann Thorac Surg 2002; 74: S1377-82.

23. Kwak YL, Oh YJ, Jung SM, Yoo KJ, Lee JH, Hong YW. Change in right ventricular function during off-pump coronary artery bypass graft 
surgery. Eur J Cardiothorac Surg 2004; 25: 572-7.

24. Gorcsan J 3rd, Murali S, Counihan PJ, Mandarino WA, Kormos RL. Right ventricular performance and contractile reserve in patients with severe heart failure. Assessment by pressure-area relations and association with outcome. Circulation 1996; 94: 3190-7.

25. Jaski BE, Fifer MA, Wright RF, Braunwald E, Colucci WS. Positive inotropic and vasodilator actions of milrinone in patients with severe congestive heart failure. Dose-response relationships and comparison to nitroprusside. J Clin Invest 1985; 75: 643-9.

26. Bailey JM, Levy JH, Kikura M, Szlam F, Hug CC Jr. Pharmacokinetics of intravenous milrinone in patients undergoing cardiac surgery. Anesthesiology 1994; 81: 616-22.

27. Lobato EB, Janelle GM, Urdaneta F, Martin TD. Comparison of milrinone versus nitroglycerin, alone and in combination, on grafted internal mammary artery flow after cardiopulmonary bypass: effects of alpha-adrenergic stimulation. J Cardiothorac Vasc Anesth 2001; 15: 723-7.

28. Baruch L, Patacsil P, Hameed A, Pina I, Loh E. Pharmacodynamic effects of milrinone with and without a bolus loading infusion. Am Heart J 2001; 141: 266-73.

29. Perings SM, Perings C, Kelm M, Strauer BE. Comparative evaluation of thermodilution and gated blood pool method for determination of right ventricular ejection fraction at rest and during exercise. Cardiology 2001; 95: 161-3.

30. Urban P, Scheidegger D, Gabathuler J, Rutishauser W. Thermodilution determination of right ventricular volume and ejection fraction: a comparison with biplane angiography. Crit Care Med 1987; 15: 652-5.

31. Samuelsson S, Ehrenberg J, Settergren G. Clinical estimation of left and right ventricular volume with open chest compared with transesophageal echocardiography and fast-response thermodilution. J Cardiothorac Vasc Anesth 1995; 9: 670-5.

32. Biswas S, Clements F, Diodato L, Hughes GC, Landolfo K. Changes in systolic and diastolic function during multivessel off-pump coronary bypass grafting. Eur J Cardiothorac Surg 2001; 20: 913-7. 